\title{
Hernioplastia experimental em coelhos por meio de cartilagem auricular bovina conservada em glutaraldeído
}

[Rabbits experimental hernioplasty by means of bovine auricular cartilage preserved in glutaraldehyde]

\author{
L.A.F. Silva ${ }^{1,6}$, L.G. Franco ${ }^{2}$, L.B. Menezes ${ }^{3}$, V.M.B.D. Moura ${ }^{1}$, K.M. Bernardes ${ }^{4}$, M.A. Souza ${ }^{5}$ \\ ${ }^{1}$ Escola de Veterinária - UFG - Goiânia, GO \\ ${ }^{2}$ Aluno de pós-graduação - EV-UFG - Goiânia, GO \\ ${ }^{3}$ Instituto de Patologia Tropical e Saúde Pública - UFG - Goiânia, GO \\ ${ }^{4}$ Aluno de graduação - EV-UFG (Bolsista de Iniciação Científica) - Goiânia, GO \\ ${ }^{5}$ Universidade Federal de Mato Grosso - UFMT - Sinop, MT \\ ${ }^{6}$ Bolsista do $\mathrm{CNPq}$
}

\begin{abstract}
RESUMO
Avaliou-se a viabilidade do emprego da cartilagem auricular bovina conservada em glutaraldeído a $4 \%$ na hernioplastia experimental, empregando-se seis coelhos adultos, machos, da raça Nova Zelândia. Para obtenção da hérnia incisional, removeu-se um segmento elíptico de $3 \mathrm{~cm}$ de comprimento por $1 \mathrm{~cm}$ de largura, no ponto central à primeira incisão, envolvendo fáscia e tecido muscular, na região da cicatriz umbilical. Dois animais de cada vez foram sacrificados aos 15, 30 e 45 dias após a cirurgia. Nos sacrificados aos 15 dias, observaram-se áreas focais de inflamação, caracterizadas por abscesso e fístula. À microscopia, observou-se área de inflamação e necrose próxima à periferia do implante. Nas amostras colhidas dos animais sacrificados aos 30 dias, não foram evidenciadas alterações clínicas relevantes. Desses, um animal apresentou à microscopia intensa proliferação fibroblástica, moderada neovascularização e células inflamatórias predominantemente mononucleares. Dos sacrificados aos 45 dias, em um ocorreu aderência de alça intestinal ao implante. É possível inferir que o material implantado apresentou satisfatória compatibilidade com o tecido receptor. Conclui-se que o implante de cartilagem auricular bovina conservada na hernioplastia experimental em coelhos apresentou evidências de boa integração tecidual e cicatrização, não havendo eliminação do material implantado.
\end{abstract}

Palavras-chave: coelho, hérnia incisional, lagomorfos, cirurgia experimental

\begin{abstract}
The auricular cartilage preserved in 4\% glutaraldehyde was used for experimental hernioplasty in six male, adult, New Zealand rabbits. To create an incision hernia, an elliptic tissue fragment three centimeter-long and one-centimeter wide was removed at a point centrally located from the first incision, embracing fascia and muscle tissue, from the area of umbilical scar. Animals were euthanized, two at a time, 15, 30, or 45 days after surgery. In the animals euthanized after 15 days focal areas of inflammation were observed, characterized by abscesses and fistulas. The histological section showed areas of inflammation and necrosis next to the periphery of the graft. In the animals euthanized after 30 days, there was no evidence of clinical alterations. Microscopic diagnosis of one of these animals showed intense fibroblastic proliferation, moderate neovascularization and inflammatory cells, predominantly mononuclear. One of the animals submitted to euthanasia at 45 days presented at necropsy adherence of bowel to the graft and impaired reconstitution of the parietal peritoneum. It is possible to infer that the grafted material presented satisfactory compatibility with the receptor tissue. Thus, it may be concluded that auricular bovine cartilage grafts preserved in 4\% glutaraldehyde in experimental hernioplasty in rabbits presented evidence of good tissue integration and healing, with no elimination of the grafted material.
\end{abstract}

Keywords: rabbit, incisional hernia, experimental surgery

Recebido em 8 de outubro de 2008

Aceito em 6 de abril de 2009

E-mail: lafranco@vet.ufg.br 


\section{INTRODUÇÃO}

A substituição de tecidos orgânicos em perdas estruturais anatômicas decorrentes de má formação congênita ou traumatismos compreende um dos principais desafios da cirurgia, sendo empregados diferentes materiais para esse fim, sejam sintéticos ou biológicos (Santillán-Doherty et al., 1995; Quitzan et al., 2003). Em medicina veterinária, utilizam-se, frequentemente, os implantes biológicos, especialmente na reconstrução dos músculos do diafragma e da parede abdominal (CárdenasLaislon et al., 1997; Mazzanti et al., 2000).

No tratamento de hérnias, sobretudo as recorrentes com ausência de tecido íntegro para fechamento do anel herniário, além das membranas sintéticas, como as telas de polipropileno, poliéster e poliuretano (Quitzan et al., 2003), o emprego de implantes biológicos conservados é relativamente comum (Shoukry et al., 1997; Raiser et al., 2001; Rabelo et al., 2004).

A cartilagem auricular bovina, apesar de possuir grandes vasos em sua superfície, não apresenta capilares intracartilaginosos (Banks, 1992). O tecido cartilaginoso apresenta capacidade para adaptar-se à área receptora, sendo moldado e completamente envolvido pelo tecido do hospedeiro. É utilizado para constituir um arcabouço para o desenvolvimento de tecidos do receptor, podendo permanecer no leito hospedeiro durante tempo indefinido (Gabrielli et al., 1986; Baungarten et al., 2007). Tais aspectos histomorfológicos caracterizam-na como membrana biológica útil para implante em diversos procedimentos cirúrgicos. O material é de fácil obtenção e preparo, é resistente e apresenta baixo custo, características que reforçam tal indicação (Costa, 2003).

Como ocorre com outros implantes biológicos, a cartilagem auricular requer conservação, tanto para preservação da viabilidade quanto para a diminuição da antigenicidade, desejável na maioria dos casos. Dentre os métodos químicos de conservação, destacam-se o ácido acético glacial, glicerina, solução supersaturada de açúcar e glutaraldeído (Richa, 1987; Paulo, 1997; D'Oliveira, 1999; Martins et al., 2000) O glutaraldeído é um antisséptico e desinfetante pouco irritante e de amplo espectro bactericida
(Cárdenas-Lailson et al., 1997). Gallo et al. (1982), ao utilizarem a solução de glutaraldeído na conservação de pericárdios bovino e suíno para fins de implantação, concluíram que houve manutenção macro e microscópica das estruturas morfológicas do implante, assim como baixa antigenicidade.

O objetivo deste estudo foi avaliar a utilização de cartilagem auricular bovina conservada em glutaraldeído a 4\% na hernioplastia experimental em coelhos por meio de avaliações clínicas e histológicas.

\section{MATERIAL E MÉTODOS}

Após aprovação pelo Comitê de Ética em Pesquisa da Universidade Federal de Goiás, o experimento foi realizado utilizando-se seis coelhos machos, saudáveis, da raça Nova Zelândia, com média de idade e peso de seis meses e $2,7 \mathrm{~kg}$, respectivamente. Os animais alojados em gaiolas individuais receberam alimentação duas vezes ao dia e água à vontade, durante o período experimental.

As cartilagens foram obtidas de aurículas bovinas, após remoção da pele e do tecido subcutâneo. O material, lavado em água corrente para eliminar excessos de tecidos e sangue, foi encaminhado ao laboratório sob refrigeração. Concluído o processo de limpeza, as cartilagens foram submersas em solução de polivinilpirrolidona-iodo (PVPI) ${ }^{1}$ a $1 \%$, por 24 horas, em frascos identificados. Ao final desse período, o material foi lavado com solução de cloreto de sódio a $0,9 \%^{2}$, para remoção dos resíduos de PVPI. Na sequência, o material foi conservado em frascos esterilizados contendo glutaraldeído a 4\%, durante 30 dias antecedentes à realização dos implantes, conforme recomendação de Silva et al. (2005).

Após o processo de conservação, verificou-se a ausência de contaminação do material. Com o auxílio de pinças e tesoura esterilizadas, colheram-se, em capela de fluxo laminar, fragmentos de $2 \times 2 \mathrm{~cm}$ de cada cartilagem conservada. As amostras, individualmente, foram transferidas para tubos de ensaio contendo caldo

\footnotetext{
${ }^{1}$ Indústria farmacêutica Rioquímica Ltda - São José do Rio Preto, Brasil.

${ }^{2}$ Halex Indústria Farmacêutica Ltda - Goiânia, Brasil.
} 
tiogliconato e selenito cistina. Os exames microbiológicos foram realizados de acordo com as técnicas de rotina de laboratório, com a finalidade de avaliar a capacidade do conservante em manter o material biológico a ser implantado em condições assépticas. A ausência de contaminação das cartilagens resultaria em condição estabelecida para evitar possível associação entre o uso do material séptico e eventuais complicações pós-cirúrgicas. Portanto, amostras que apresentaram crescimento bacteriano após o processo de conservação não foram empregadas neste estudo.

Os seis implantes foram realizados no mesmo dia, utilizando-se materiais e instrumentais cirúrgicos individuais e esterilizados. $\mathrm{O}$ período pré-operatório constou de tricotomia e antissepsia do abdômen ventral dos coelhos, sendo empregada com solução de PVPI a 1\%. Para o procedimento anestésico, utilizou-se a associação de $30 \mathrm{mg} / \mathrm{kg}$ de cetamina ${ }^{3}$ e $4,0 \mathrm{mg} / \mathrm{kg}$ de diazepam ${ }^{4}$ aplicados por via intramuscular. Posteriormente, realizou-se incisão cutânea préretro umbilical, de aproximadamente cinco centímetros na linha média e, sequencialmente, obteve-se uma hérnia incisional, removendo-se um segmento elíptico de três centímetros de comprimento por um centímetro de largura, no ponto central à primeira incisão, envolvendo fáscia e tecido muscular. Paralelamente, à medida que se preparava o anel herniário, efetuava-se o processamento das cartilagens a serem implantadas, enxaguando os fragmentos repetidamente em solução de cloreto de sódio a $0,9 \%$, visando remover resíduos da solução conservante de glutaraldeído a 4\%. Os implantes foram acondicionados em cubas contendo solução de cloreto de sódio a $0,9 \%$, à temperatura ambiente, durante dez minutos para hidratação, conforme metodologia proposta por Paulo (1997). Sequencialmente, realizou-se adequação do tamanho da cartilagem auricular ao diâmetro do anel herniário confeccionado, fixando-a na parede abdominal, por meio de quatro pontos de reparo, distribuídos nos vértices e nos pontos médios das bordas do anel, utilizando-se fio de náilon 3-0 e sutura em padrão Wolf. A justaposição e a fixação das

\footnotetext{
${ }^{3}$ Agener União Química Farmacêutica Nacional S/A - Taboão da Serra, Brasil.

${ }^{4}$ Cristália Produtos Químicos Farmacêuticos Ltda - Itapira, Brasil.
}

bordas do fragmento à fáscia abdominal externa foram realizadas em sutura padrão contínuo simples, empregando-se o mesmo tipo de fio, que também foi utilizado na sutura cutânea em padrão simples separado.

No pós-operatório, empregaram-se, por via IM, $5,0 \mathrm{mg} / \mathrm{kg}$ de enrofloxacina ${ }^{5}$ a $2,5 \%$, a cada 24 horas, por cinco dias consecutivos e $1,0 \mathrm{mg} / \mathrm{kg}$ de flunixin meglumine ${ }^{6}$ IM, uma vez ao dia por três dias consecutivos. A higienização e as avaliações clínicas da ferida cirúrgica foram realizadas diariamente até a retirada dos pontos. Dois animais de cada vez foram submetidos à eutanásia, escolhidos ao acaso, aos 15, 30 e 45 dias do procedimento cirúrgico. Como método de eutanásia, optou-se pela aplicação de solução de cloreto de potássio ${ }^{7}$ a $10 \%$, após anestesia geral profunda, com tiopental sódico ${ }^{4}$, conforme recomendações do Colégio Brasileiro de Experimentação Animal.

A avaliação clínica da ferida cirúrgica foi realizada, sistematicamente, a cada 24 horas. Foram considerados a presença de processo inflamatório, a deiscência de ferida e abscesso no sítio de implante. A ausência de integração entre o implante e a musculatura abdominal, ou seja, a eliminação do implante, foi considerada quando da presença de extensas áreas de necrose tanto do tecido receptor quanto da cartilagem implantada, assim como da presença concomitante de inflamação intensa e difusa nestes mesmos sítios.

Para a avaliação histológica, colheram-se amostras de tecido que envolvia a inserção entre a parede abdominal e o implante, posteriormente fixadas em formol tamponado a $10 \%$, durante 48 horas, e processadas conforme métodos rotineiros de inclusão em parafina. Sequencialmente, com o auxílio de micrótomo rotativo, obtiveram-se cortes histológicos de três micrômetros, que foram corados pela técnica de hematoxilina e eosina (Luna, 1968).

A análise histológica foi realizada empregandose microscópio de luz, sendo considerado como parâmetro principal de indicação da integração dos fragmentos de cartilagem enxertados a

${ }^{5}$ Chemitec Agro-Veterinária - São Paulo, Brasil.

${ }^{6}$ Schering-Plough Saúde Animal Indústria e Comércio Ltda Cotia, Brasil.

${ }^{7}$ Aster - Sorocaba, Brasil. 
presença de cicatrização nas regiões periférica e central do fragmento. A cicatrização foi caracterizada pelas fases de tecido de granulação e maturação ou fibroplasia, já que as primeiras amostras foram colhidas aos 15 dias póscirúrgico, período em que já não se observam as fases cicatriciais iniciais de limpeza e retração. Verificou-se, ainda, a presença de contaminação bacteriana, necrose, tecido conjuntivo e infiltrado leucocitário com células polimorfonucleares, mononucleares e/ou multinucleadas. A depender da presença, intensidade e distribuição das variáveis supracitadas, bem como da concomitância dessas com resposta tecidual cicatricial, ponderou-se a ocorrência de processo inflamatório secundário à contaminação da ferida.

Os dados relativos às avaliações clínicas e histológicas do procedimento foram avaliados por meio de estatística descritiva (Sampaio, 1998).

\section{RESULTADOS E DISCUSSÃO}

A avaliação clínica diária e sistemática dos indivíduos permitiu identificação macroscópica de áreas focais de inflamação nos dois animais submetidos à eutanásia aos quinze dias. Observou-se presença de abscesso em um animal e fístula em outro. Ao exame histológico do material colhido nos sítios cirúrgicos, foi possível confirmar área de inflamação próxima à periferia do implante. Quanto ao material implantado, observou-se manutenção da normalidade na histomorfologia da cartilagem (Fig. 1A). Com relação às demais áreas avaliadas, especialmente relacionadas à pele, os dois animais exibiram características microscópicas da fase de granulação da cicatrização (Fig. 1B).

Acredita-se que a presença de complicações como abscesso e fístula esteja ligada principalmente à contaminação nesse período, visto que o procedimento cirúrgico foi realizado dentro das condições adequadas de antissepsia, e o implante utilizado foi devidamente conservado, não havendo crescimento de microrganismos. $\mathrm{O}$ processo inflamatório observado nas amostras obtidas aos quinze dias também não pode ser atribuído à má conservação do material, já que todas as cartilagens foram colhidas e preparadas simultaneamente, e os demais animais implantados não apresentaram reação inflamatória semelhante.

Apesar da presença de contaminação evidenciada nos dois animais, não houve eliminação do implante em nenhum caso, o que corrobora com os achados microscópicos de ausência de resposta inflamatória hiperaguda e disseminada. Para Razani et al. (1990), a permanência dos implantes no sítio operatório durante a primeira semana está diretamente condicionada à ausência desse tipo de reação inflamatória.

Relativamente à avaliação clínica das feridas cirúrgicas dos animais sacrificados aos 30 dias, não se evidenciaram alterações clínicas relevantes. Ao exame microscópico das amostras obtidas de um dos animais no mesmo período, observaram-se intensa proliferação fibroblástica, moderada neovascularização e células inflamatórias predominantemente mononucleares, com presença de células gigantes (Fig. 1C). Achados semelhantes foram descritos por Quitzan et al. (2003), ao compararem uma malha comercial de poliéster com o pericárdio bovino preservado em glicerina na reconstituição de defeitos da parede abdominal. Na avaliação da outra amostra referente aos 30 dias, constataramse fibroplasia, discreto tecido de granulação e raras células gigantes, caracterizando a fase de resolução do processo cicatricial. Nenhum implante foi eliminado nos animais sacrificados aos 30 dias. De forma semelhante, Braccialli et al. (2001), ao avaliarem o implante de cartilagem auricular bovina na correção cirúrgica auricular canina, descreveram ausência de rejeição do implante durante o mesmo período de avaliação. Gabrielle et al. (1986) descreveram que implantes de tecidos biológicos apresentam capacidade temporal indefinida de permanência no leito receptor.

À necropsia, em um dos animais observou-se presença de aderência do omento à área circundando o implante. Tal fato pode estar associado ao trauma mecânico e consequente isquemia do peritônio em decorrência do defeito realizado na parede abdominal e do implante da cartilagem. Jackson et al. (1991) relatou que a utilização de próteses ou biomateriais em cirurgias abdominais pode resultar em traumas, favorecendo a migração do omento em direção à área peritoneal, caracterizando-se como fase 
dinâmica do processo de cicatrização. Stopiglia et al. (1986), ao avaliarem o implante de pericárdio equino conservado em glicerina na parede torácica de cães, observaram resultados semelhantes com presença de aderência do pericárdio implantado à pleura pulmonar.

Dos animais submetidos à eutanásia aos 45 dias, um animal apresentou à necropsia aderência de alça intestinal ao implante e reconstituição deficiente do peritônio parietal. Achados semelhantes foram apontados por Melo et al. (2003), ao avaliarem o efeito da prótese de polipropileno no espaço pré-peritoneal em cães. Ao exame microscópico da amostra colhida do referido animal, observou-se moderado infiltrado inflamatório e fibroplasia. A presença de um moderado número de células fibroblásticas respalda a afirmação de que, aos 45 dias, a ferida cirúrgica estivesse na fase de resolução do processo cicatricial. Desse modo, é esperado que o número de fibroblastos aumente no início da reparação e depois diminua, seja pela sua própria maturação ou por estar finalmente entre as fibras colágenas que produziu, conforme apontado por Haddad et al. (2004). No outro animal, o exame histológico foi compatível com a fase de resolução da cicatrização, não havendo sinais de inflamação ou rejeição (Fig. 1D).

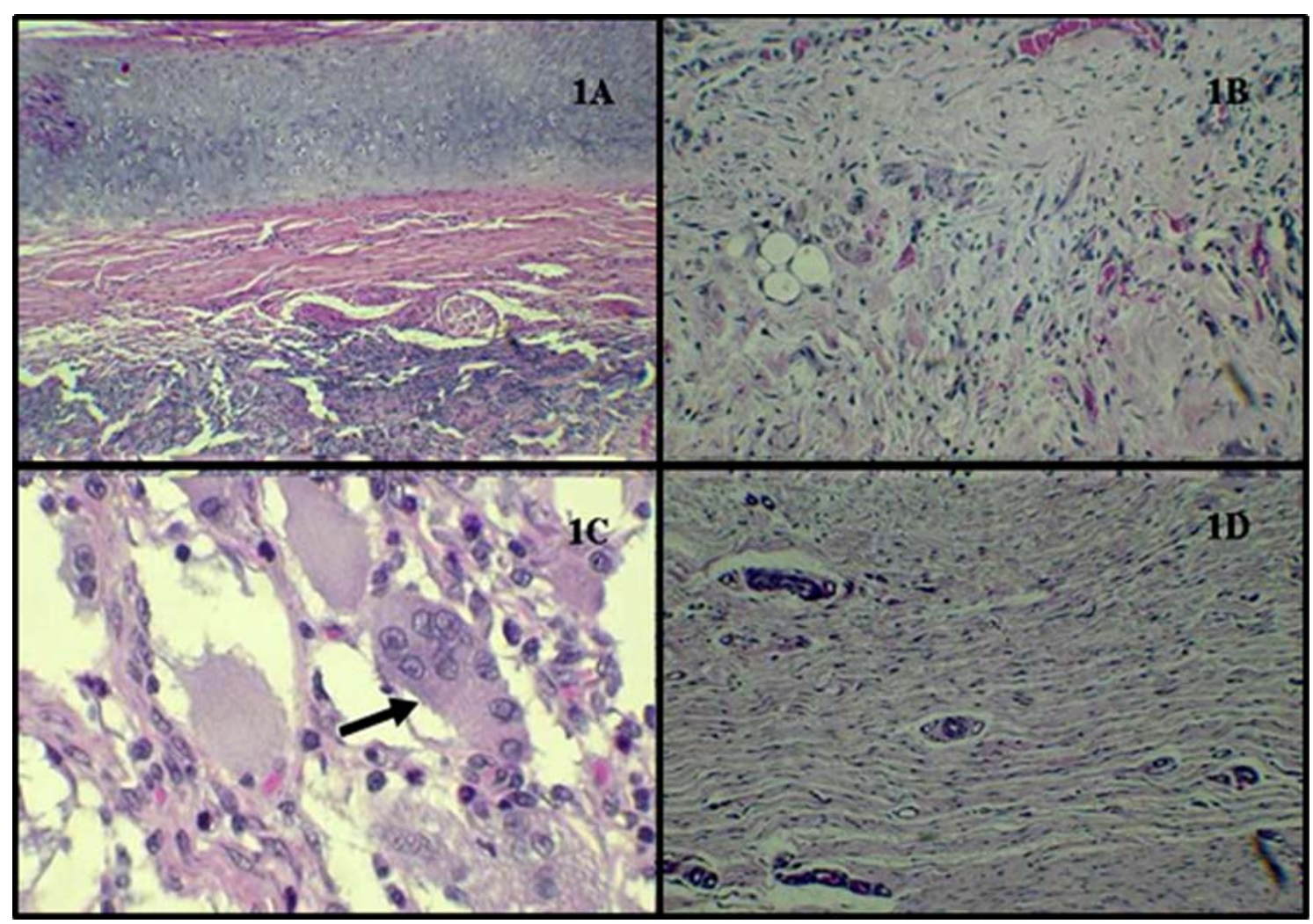

Figura 1. Coelho. Avaliação histológica da região implantada aos 15, 30 e 45 dias após o procedimento cirúrgico. 1A: área do implante aos 15 dias, observa-se presença de inflamação e necrose abaixo do implante de cartilagem; 1B: no mesmo período, nota-se presença de tecido de granulação com neovascularização e proliferação fibroblástica proeminentes; 1C: aos 30 dias, observa-se presença de células multinucleadas (seta); 1D: aos 45 dias após o implante, nota-se a organização de tecido conjuntivo, característica da fase de resolução e cicatrização. (HE, 400X).

Apesar das intercorrências observadas, em nenhum dos animais detectaram-se processos de mineralização do enxerto ou do leito do receptor, tal como foi observado por pesquisadores, que estudaram a conservação de tecido cartilaginoso por meios químicos e físicos, observando processos fibrosos relevantes e, em alguns casos, deposição de tecido cartilaginoso ausente ou mutilado (Santiago, 1989). Não foram observadas áreas de reabsorção da cartilagem 
implantada em nenhum animal, diferente dos resultados de Baungarten et al. (2007), que avaliaram a reconstrução de pálpebra inferior de coelhos, com enxerto de cartilagem auricular alógena, conservada em solução saturada de $\mathrm{NaCl}$. Esses autores verificaram ausência de cartilagem auricular nos animais submetidos ao enxerto palpebral, sugerindo a absorção do tecido implantado.

Considerando os achados clínicos e histopatológicos observados nas diferentes fases de avaliação, é possível inferir que o material implantado apresentou satisfatória compatibilidade com o tecido receptor, não havendo em nenhum momento avaliado eliminação dos implantes. Além disso, todas as amostras avaliadas apresentaram características de cicatrização evidenciadas pela observação de tecido de granulação e fibroplasia que se desenvolveram e evoluíram nos três momentos estudados. Nos animais submetidos à eutanásia aos 15 dias, apesar da presença de contaminação, os sinais de neovascularização e a intensa proliferação fibroblástica indicaram evolução cicatricial positiva do processo.

Assim, nas condições em que o presente estudo foi desenvolvido, é possível concluir que o implante de cartilagem auricular bovina conservada em glutaraldeído a $4 \%$ na hernioplastia experimental em coelhos apresenta evidências de boa integração tecidual e cicatrização, e que não há eliminação de material implantado.

\section{REFERÊNCIAS BIBLIOGRÁFICAS}

BANKS, W.J. Tecido de sustentação: cartilagem. In: . Histologia veterinária aplicada. 2.ed. São Paulo: Manole, 1992. p.124-136.

BAUNGARTEN, L.B.; FREITAS, P.M.C.; EURIDES, D. et al. Blefaroplastia em coelhos por meio de cartilagem auricular alógena conservada em solução saturada de $\mathrm{NaCl}$. Arq. Bras. Med. Vet. Zootec., v.59, p.1219-1223, 2007.

BRACCIALLI, C.S.; DALECK, C.R.; COSTA NETO, J.M. et al. Implante de cartilagem auricular de bovino, conservada em glicerina a $98 \%$, na aurícula de cães. Vet. Not., n.7, p.53-59, 2001 .
CARDENAS-LAILSON, L.E.; GLAVANMONTANO, A.; MALAGON-HIDALGO, H.O. Modelo experimental del uso de pericardio de bovino tratado con glutaraldehído, comparado com malla de silicón para el tratamiento de los defectos congénitos de la parede abdominal. Cir. Gen., v.19, p.116-119, 1997.

COSTA, J.L.O. Acetabuloplastia extracapsular em cães com cartilagem auricular de bovino conservada com glicerina. 2003. 84f. Tese (Doutorado) - Faculdade de Ciências Agrárias e Veterinárias, Universidade Estadual Paulista, Jaboticabal.

D’OLIVEIRA, K.S. Reparação cirúrgica extraarticular da ruptura do ligamento cruzado cranial de cão (Canis familiaris) com centro frênico heterólogo preservado em glicerina. 1999. 57f. Dissertação (Mestrado) - Faculdade de Medicina Veterinária e Zootecnia, Universidade de São Paulo, São Paulo.

GABRIELLE, M.F.R.; VICENZO, P.; SNATIMERO, S.A. et al. Autogenous transplantation of rib cartilage, preserved in glycerol, tothe malar process of rats: a histological study. J. Nikon Univ. Sch. Dent., v.28, p.87-99, 1986.

GALLO, J.I.; ARTIÑANO, E.; VAL, F. Glutaraldehyde-preserved heterologous pericardium for the repair of diaphragmatic defects. J. Thorac. Cardiovasc. Surg., v.83, p.905-908, 1982.

HADDAD, D.F.; MARQUES, A.; KAFEJIANHADDAD, A.P. et al. Estudo comparativo das reações teciduais ao implante de pericárdio bovino e a inclusão de politetrafluoroetileno expandido em ratos. Acta. Cir. Bras., v.19, p.131-135, 2004.

JACKSON, B.A.; SCHWANE, J.A.; STARCHER, B.C. Effect of ultrasound therapy onrepair of Achilles' tendon injuries in rats. Med. Sci. Sports Exerc., v.23, p.171-176, 1991.

LUNA, L.G. Manual of histologic staining methods of the Aimed Forces Institute of Pathology. 3.ed. New York: McGraw Hill, 1968. $257 \mathrm{p}$.

MARTINS, E., MARTINS, V.M.V., MARQUES JÚNIOR, A.P. et al. Bovine placentome preservation for light microscopy evaluation. Arq. Bras. Med. Vet. Zootec., v.52, p.117-124, 2000. 
MAZZANTI, A.; PIPPI, N.L.; RAISER, A.G. et al. Análise do músculo diafragma de cão conservado em glicerina a $98 \%$ em temperatura ambiente. In: CONGRESSO BRASILEIRO DE CIRURGIA E ANESTESIOLOGIA VETERINÁRIA， 4., 2000, Goiânia. Anais... Goiânia: CBCAV, 2000. p.98. (Resumo).

MELO, R.S.; GOLDENBERG, S.; LEAL, A.T. et al. Efeitos da prótese de polipropileno colocada por inguinotomia no espaço préperitoneal em cães. Avaliação laparoscópica e microscópica. Acta. Cir. Bras., v.8, p.289-296, 2003.

PAULO, N.M. Estudo comparativo entre membrana amniótica de equino preservada em glicerina a 98\% e em ácido acético glacial a $0,25 \%$ no tratamento de feridas cutâneas experimentais no cão. 1997. 62f. Tese (Doutorado) - Faculdade de Medicina Veterinária e Zootecnia, Universidade de São Paulo, São Paulo.

QUITZAN, J.G.; RAHAL, S.C.; ROCHA, N.S. Comparação entre pericárdio bovino preservado em glicerina e malha de poliéster no reparo de falhas da parede abdominal em ratos. Acta Cir. Bras., v.18, p.301-308, 2003.

RABELO, R.E.; FERNANDES, J.J.R.; LIMA, C.R.O. et al. Uso da cartilagem auricular bovina conservada em glicerina a $98 \%$ como implante heterólogo na hernioplastia umbilical de ovino. In: CONGRESSO DO COLÉGIO BRASILEIRO DE CIRURGIA E ANESTESIOLOGIA, 4., 2004, Indaiatuba. Anais... Indaiatuba: CBCAV, 2004. p.246-247.

RAISER, A.G; GRAÇA, D.L; PIPPI, N.L. et al. Homoimplante ortópico de tendão calcâneo em cães. Conservação, assepsia e implantação. Ciênc. Rural. v.31, p.89-94, 2001.
RANZANI, J.J.T.; GANDOLFI, W.; FRANCO $M$. et al. Implante de pericárdio de equino conservado em glicerina em solução de continuidade do diafragma de cão. Braz. J. Vet. Res. Anim. Sci., v.27, p.65-73, 1990.

RICHA, R.V.R. Nuestra experiencia en glicerina en el tratamiento de las grandes hernias ventrales. Rev. Med., v.19, p.109-117, 1987.

SAMPAIO, I.B.M. Estatística aplicada à experimentação animal. Belo Horizonte: FEPMVZ, 1998. 221p.

SANTIAGO, J.L. Avaliações histológicas de transplantes autógenos de cartilagem hialina natural e termicamente tratada em coelhos (Oryctollagus cunicullus I). 1989. 57f. Tese (Doutorado) - Faculdade de Odontologia, Universidade de São Paulo, São Paulo.

SANTILLÁN-DOHERTY, O.; PATRICIO, J.V.R.; SOTRES-VEGA, A. et al. Reparación de defectos de pared tóracoabdominal de perros con bioprótesis de pericardio bovino. Rev. Invest. Clin., v.47, p.439-446, 1995.

SILVA, L.A.F.; SILVA, O.C.; EURIDES D. et al. Hernioplastia umbilical em bovino: emprego de implante de cartilagem auricular homóloga e avaliação clínica dos resultados. Acta Sci. Vet., v.33, p.57-62, 2005.

SHOUKRY, M.; EL KEIEY, M.; HAMOUDA, $M$. et al. Comercial polyester fabric repair of abdominal hernias and defects. Vet. Rec., v.28, p.606-607, 1997.

STOPIGLIA, A.J.; ALVARENGA, J.; MORAIS BARROS, P.S. et al. Reparation chirurgical de la paroi thoracique Du chien. Point Vet., v.18, p.239-243, 1986. 